http://jmscr.igmpublication.org/home/ ISSN (e)-2347-176x ISSN (p) 2455-0450

crossref DOI: https://dx.doi.org/10.18535/jmscr/v8i1.130

\title{
Neuro Behavioral Outcome of Neonatal Hypothyroidism by Using Brazelton NBAS- A Cohort Study
}

\author{
Authors \\ Lalit Agrawal', Dr Sasmita Devi Agrawal2*, Satish kumar Sethi³, \\ Asit Mohan Mohapatra ${ }^{4}$, Hemant Agrawal $^{5}$ \\ ${ }^{1} 3^{\text {rd }}$ Year Postgraduate Trainee, Department of Pediatric, Hitech Medical College \& Hospital, \\ Bhubaneswar, Odisha, India \\ $2^{*}$ Professor, Department of Pediatrics, Hitech Medical College \& Hospital, Bhubaneswar, Odisha, India \\ ${ }^{3} 2^{\text {nd }}$ Year Postgraduate Trainee, Department of Pediatrics, Hitech Medical College \& Hospital, \\ Bhubaneswar, Odisha, India. \\ ${ }^{4} 2^{\text {nd }}$ Year Postgraduate Trainee, Department of Pediatrics, Hitech Medical College \& Hospital, \\ Bhubaneswar, Odisha, India. \\ ${ }^{5}{ }^{\text {st }}$ Year Postgraduate Trainee, Department of Pediatrics, Hitech Medical College \& Hospital, \\ Bhubaneswar, Odisha, India \\ *Corresponding Author \\ Dr Sasmita Devi Agrawal
}

\begin{abstract}
Background and Objective: Neonatal hypothyroidism is associated with poor neuro behavioral outcome in neonates. Brazelton neurobehavioral assessment scale is good alternative to assess the neurobehavioral outcome of neonates at bedside.

Design: prospective cohort study.

Setting: Department of pediatrics, Hi tech medical College, Bhubaneswar.

Participants: 30 hypothyroid newborns were enrolled and followed up at 3-4 weeks of life. The neonates were represented the case neonates.30 euthyroid healthy newborns were selected as control group.

Main Outcome Measures: Early neonatal behavioral assessment at 3-4 weeks of age.

Results: Neonatal hypothyroidism leads to poor neurobehavioral outcome in newborn as already known and also by NBAS scoring. Early treatment has good outcome in terms of Neurrologicaland behavioural status of a newborn.

Conclusion: Neonatal hypothyroidism is associated with abnormal neurobehavioral development and Brazelton NBAS is good alternative for neurobehavioral assessment at bed side.

Keywords: Neonates, neurodevelopment, Brazelton neurobehavioral assessment scale.
\end{abstract}

\section{Introduction}

Neonatal hypothyroidism, one of the commonest preventable causes of mental retardation is also the most common neonatal endocrine disorder. The subtlety of clinical features and the maternal $\mathrm{h}$ hormone crossing the placenta provides a protective effect on the fetal brain masking the clinical signs. In 
addition to this even the most severe forms of neonatal hypothyroidism have some functioning residual thyroid tissue further making clinical diagnosis difficult.

To prevent further brain injury, treatment needs to be started as early as possible after birth.

NBAS has evolved as the good alternative to detect infants with poor neurobehavioral response as in hypothyroidism.

By using Brazelton neurobehavioral assessment scale the neurobehavioral outcome of a neonate with hypothyroidism can be assessed at 3-4 weeks of life and intervention can be done at neonatal age only.

\section{Methods}

The present prospective study was undertaken at Hi Tech Medical College, Bhubaneswar, Odisha. During the period of October 2017to November 2020. The study cohort was selected from department of pediatrics.

Total 60 Newborns were enrolled. 30 newborns with raised TSH level, who presented the case and 30 as controll group.

Ethical clearance was obtained from institutional Ethical committee and written informed consent was taken from all participants. All newborns enrolled were assessed within 7 days of life and again at 3-4 weeks of postnatal life.

The study participants were categorised into following subgroups:

Control group $(\mathrm{n}=30)$ with TSH $<4.4 \mathrm{miu} / \mathrm{l}$

Treated group $\quad(n=12)$ with TSH $>10 \mathrm{miu} / \mathrm{l}$

Non trered group. $(n=18)$ with TSH Between 6$10 \mathrm{miu} / 1$

The serum TSH was assessed between $72 \mathrm{~h}$ of life and 7 days of postnatal life.

Early neonatal behavioural assessment was done at 3-4 weeks of age using Brazelton neurobehavioral assessment scale (NBAS). The scale contains 7 clusters of 31 items both neurological and supplementary that measures the quality of responsiveness and the amount of input that the infant needs from the examiner to show his or her best performance. All the items were scored in the correct state as defined in the NBAS guidelines.]

WHAT IS ALREADY KNOWN?
- Neonatal hypothyroid is a risk factor for
adverse neurobehavioral outcome in
neonates.
WHAT THIS STUDY AIDS?
-Brazelton NBAS is good alternative to
assess the neurobehavioral outcome of
neonates at bedside.

\section{Methodology}

$\mathrm{C}$ is control group with 30 numbers of observations shows highest average scorings for each category of test, which shows healthy response of child due to non-presence of neonatal hypothyrodism. Neonatal hypothyrodism treated group (T) shows better NBAS scoring compared to non treated group (NT).

Brezelton scoring of 31 numbers of test is dependent on each other. To estimate the impact of treatment of hypothyroidism on NBAS scoring, first we will create an index to judge the aggregate of NBAS scoring using principal component analysis (PCA). PCA method will convert these 31 test parameters into few independent components, which will be used to calculate the final aggregate value of NBAS scoring. These independent components will give unbiased

index called as Fscore to overall judge the health of child. Finally, using linear regression analysis the impact of treatment of hypothyroidism, age, HC, length, TSH level is estimated on the Brezelton score. 

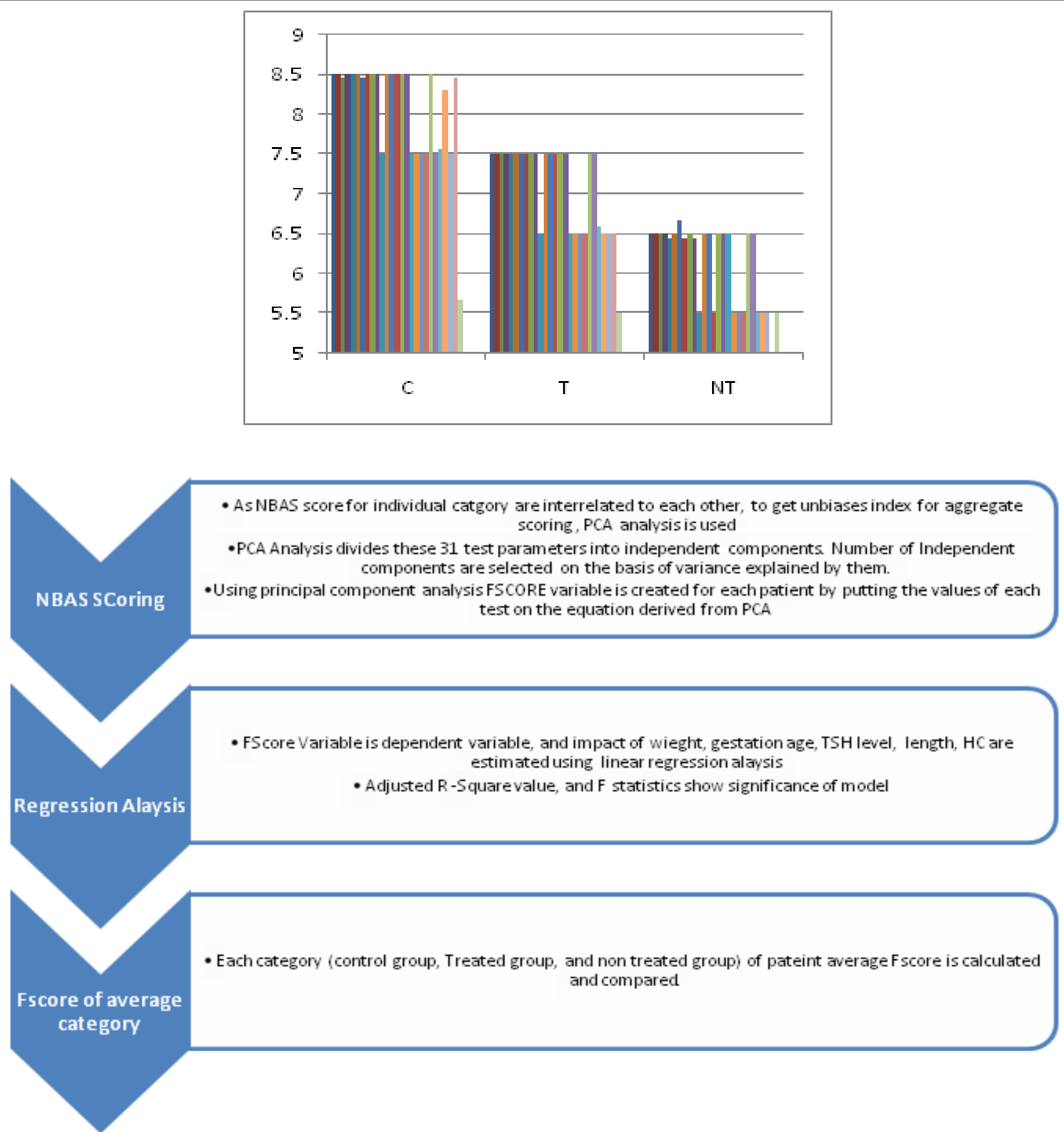

Dummy Variable Creation for Control, dummy for treated group is zero, the combine Treatment, and Non Treatment group:

When dummy control group value is zero and dummy for treated group is zero, the combine set represents control group in our study. When value of dummy control group is one and set represents non treated group. While dummy for control group is one and dummy for treated group one, this combine set represents treated group.

\begin{tabular}{|l|c|c|}
\hline Category & Dummy control Group & Dummy for treated Group \\
\hline Control group & 0 & 0 \\
\hline Non Treated Group (NT) & 1 & 0 \\
\hline Treatment Group & 1 & 1 \\
\hline
\end{tabular}




\section{Result \& Analysis}

In the principal component analysis (PCA), we have selected 5 components as variance value is less than one for component 6 . The proportion column in PCA table shows the variation in test score for patient explained by each component in our case study. The component 1 explains $45.75 \%$ variation in final NBAS test score of patient as its proportion value is .4575 . Equation for FScore is following:

FScore $=0.4575 *$ Comp $1+0.3064 *$ Comp $2+$ $0.0733 *$ Comp $3+0.0619 *$ Comp $4+.0 .0570$

*Comp5
Using above Fscore equation, for each patient Fscore index is calculated. The mean value of Fscore for total patient comes zero with standard deviation value of 3.77 , minimum value of Fscore comes out to be -5.644 , with maximum value of 5.213. Better the Fscore for a patient, better is its NBAS scoring, which in place shows better neurological outcomes of child. Control group has highest average Fscore value as expected from our model while non treatment group has lowest.

\begin{tabular}{lcccc}
\hline Group & Mean FSCORE & Max of FSCORE & Min of FSCORE & Std Dev of FSCORE \\
\hline C & 3.148832373 & 5.213834 & 0.780467 & 1.980161209 \\
NT & -4.547659889 & -3.77883 & -5.644992 & 0.607103561 \\
T & -1.050590883 & 0.8011842 & -2.990111 & 1.752788564 \\
Complete Sets & 0 & 5.213834 & -5.644992 & 3.765885837 \\
\hline
\end{tabular}

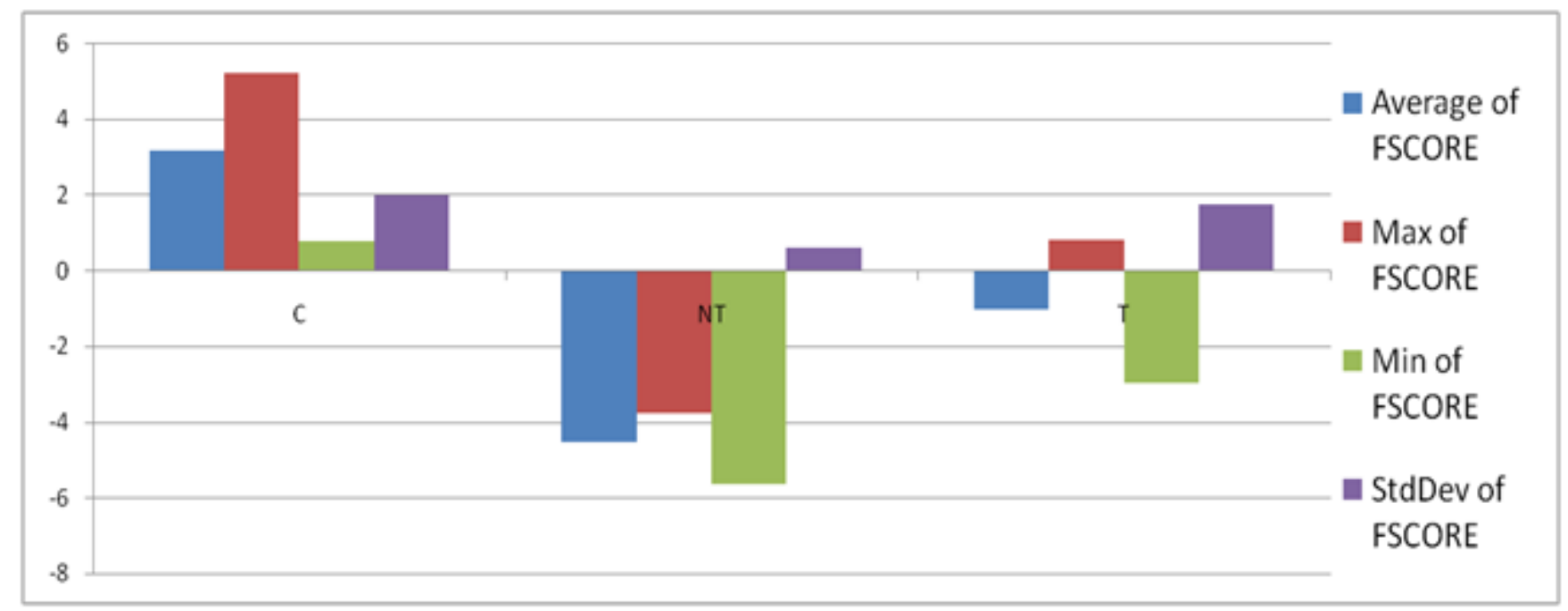

Now the Fscore calculated from above equation is used to see the impact of treatment of hypothyroidism on the neurological behavior of child. Linear regression analysis is used to estimate the impact of hypothyroidism on the Fscore index. In this model we assumed that the control group coefficient should come negative as control group (when dummy value is zero) must have better NBAS score compare to study group (when dummy for control group is one) due to non presence of hypothyroidism. The adjusted $\mathrm{R}$ square value of .8123 shows the 81.23 variability explained by our given model with $F$ statistics value of zero shows significance of our model. 


\begin{tabular}{|c|c|c|c|c|}
\hline \multicolumn{2}{|c|}{$\begin{array}{l}\text { Principal } \\
\text { components/correlation }\end{array}$} & \multicolumn{2}{|c|}{ Number of observations } & 60 \\
\hline & & \multicolumn{2}{|c|}{ Number of components } & 5 \\
\hline & & \multicolumn{2}{|c|}{ Trace } & 31 \\
\hline \multicolumn{2}{|c|}{$\begin{array}{l}\text { Rotation: } \\
\text { varimax (Kaiser off) }\end{array}$} & \multicolumn{2}{|c|}{ Rho } & 0.9561 \\
\hline Component & Variance & Difference & Proportion & Cumulative \\
\hline Comp1 & 14.1819 & 4.68237 & 0.4575 & 0.4575 \\
\hline Comp2 & 9.49953 & 7.22656 & 0.3064 & 0.7639 \\
\hline Comp3 & 2.27297 & 0.354203 & 0.0733 & 0.8372 \\
\hline Comp4 & 1.91877 & 0.152075 & 0.0619 & 0.8991 \\
\hline Comp5 & 1.7667 & & 0.0570 & 0.9561 \\
\hline
\end{tabular}

\begin{tabular}{|l|c|c|c|c|c|c|}
\hline Source & SS & $\begin{array}{c}\text { Degree of } \\
\text { Freedom }\end{array}$ & MS & \multicolumn{2}{c|}{ Number of obs } & 60 \\
\hline & & & & \multicolumn{2}{|c|}{ F( 5, 54) } & 52.07 \\
\hline Model & 692.9914 & 5 & 138.5983 & Prob > F & 0 \\
\hline Residual & 143.7404 & 54 & 2.66186 & R-squared & 0.8282 \\
\hline Total & 836.7318 & 59 & 14.1819 & Adj R-squared & 0.8123 \\
\hline \multicolumn{7}{|l|}{} \\
\hline
\end{tabular}

\section{Discussion}

Our study demonstrates that congenital hypothyroidism prevalence in our population is high and neurobehavioral development of neonates with untreated hypothyroidism is poor than treated cases of hypothyroidism.

The limitation of our study is that neurobehavioral assessment in our cohort was done between 3-4 weeks of postnatal life that may not be representative of future neurodevelopment of a child. Studies where assessment was done at later also support this observation.

To conclude, our study suggests an important link between neonatal hypothyroidism and neurobehavioral outcome of neonates and NBAS as a good alternative to assess neurobehavioral outcome of neonates at bedside. We recommend early identification of hypothyroidism in neonates and their optimal treatment to improve Neurodevelopmental outcome of hypothyroid babies.

\section{Reference}

1. Schoenmakers N, Alatzoslou KS, Chatterjee VK, Dattani M., Recent advances in central congenital hypothyroidism. The journal of Endocrinology.2015;227:R51-R71.

2. Lafranchi SH, Austin J. How should we be treating children with congenital hypothyroidism? Journal of pediatric Endocrinology and metabolism. 2007;20:559-578

3. Julvez J, Alaverez-pedrerol $\mathrm{M}$, Rebaglioto M, murica M, Forns J, 
Garcia-Esteban E.thyroxine levels during pregnancy in healthy women and early child neuro development. Epidemiology 2013;24:150-157.

4. Finken MJ, van eljsden M, Loomans EM, Vrijkotte TG, Rotteveel J, Maternal hypothyroxinemia in early pregnancy predicts Reduced performance in reaction time test in 5-6 years old pffsprings. J chin Endocrinol Metab. 2013;98:1417-26.

5. Hemmchs J, Bongers-Schokking JJ, Schenkk JJ, Ghassabian A, Schmidt HG, Visser TT.et al. Maternal thyroid function during early pregnency and cognitive functioning in early childhood. The generation $\mathrm{R}$ study. J chinendocrinol Metab 2010;95:4227-34. 